\title{
Hedgehog signaling maintains hair follicle stem cell phenotype in young and aged human skin
}

Laure Rittié, Stefan W. Stoll, Sewon Kang, *

John J. Voorhees and Gary J. Fisher

Department of Dermatology, University of Michigan, Ann Arbor, MI, USA

\section{Summary}

Skin hair follicles (HF) contain bulge stem cells (SC) that regenerate HFs during hair cycles, and repair skin epithelia following injury. As natural aging is associated with decreased skin repair capacity in humans, we have investigated the impact of age on human scalp HF bulge cell number and function. Here, we isolated human bulge cells, characterized as $\mathrm{CD}_{200} / \mathrm{KRT}^{+} 5^{+} / \mathrm{KRT}_{1} 9^{+}$cells of the $\mathrm{HF}$, by dissection-combined CD200 selection in young and aged human skin. Targeted transcriptional profiling indicates that KRT15, KRT19, Dkk3, Dkk4, Tcf3, S100A4, Gas1, EGFR and CTGF/CCN2 are also preferentially expressed by human bulge cells, compared to differentiated HF keratinocytes (KC). Our results demonstrate that aging does not alter expression or localization of these HF SC markers. In addition, we could not detect significant differences in HF density or bulge cell number between young and aged human scalp skin. Interestingly, hedgehog $(\mathrm{Hh})$ signaling is activated in human bulge cells in vivo, and down-regulated in differentiated HF KCs, both in young and aged skin. In addition, activation of Hh signaling by lentivirus-mediated overexpression of transcription factor Gli1 induces transcription of HF SC markers KRT15, KRT19, and Gas1, in cultured KCs. Together with previously reported knock-out mouse results, these data suggest a role for Hh signaling in maintaining bulge cell phenotype in young and aged human skin.

Key words: bulge; CD200; hair follicle; hedgehog; skin; stem cells.

\section{Introduction}

Tissue-specific adult stem cells (SCs) function throughout life to replace mature cells that are lost due to turnover, injury or

\footnotetext{
Correspondence

Laure Rittié, PhD, Department of Dermatology, University of Michigan, Medical Science Building I, Rm 6447, 1301 E. Catherine, Ann Arbor, MI 48109, USA. Tel.: (734) 647 7957; fax: (734) 647 0076; e-mail: Irittie@ umich.edu

*Present address: Johns Hopkins Dermatology, 1550 Orleans Street, Suite 205, Baltimore, MD 21231, USA

Accepted for publication 21 September 2009
}

disease. In skin, a population of cells in the hair follicle (HF) has been identified as multipotent SCs (HF stem cells, HFSCs) (Claudinot et al., 2005). In mouse models, HFSCs renew HF and sebaceous epithelia during normal hair cycling, as well as interfollicular epidermis after trauma (Morris et al., 2004; Ito et al., 2005; Levy et al., 2005, 2007). Thus, HFSCs are currently viewed as a promising target for therapy of pathologies that require skin regeneration (Limat et al., 2003). However, to utilize or target HFSCs for therapeutic purposes, it is critical to better understand their regulation.

Substantial progress has been made during the past several years in understanding skin HFSC biology in mice. However, human skin differs from murine skin in many aspects of HFSC biology. For instance, as opposed to the mouse HFSC niche, the so-called bulge for its protuberance, the human 'bulge' is less morphologically distinct. In addition, certain genes that are used as specific mouse HFSC markers, such as CD34 or p63, are not limited to HFSCs in human skin (Fiuraskova et al., 2005).

Human HFs consist of several concentric epithelial sheaths with the outer root sheath (ORS) forming the outermost layer. The ORS is contiguous with the basal layer of the epidermis, and separated from the dermal compartment by a basement membrane. The human HFSC niche (also referred to as the bulge) is the portion of the ORS that is localized between the insertions of sebaceous gland (SG) and arrector pili (AP) muscle (Ohyama et al., 2006). Keratin (KRT) 15 and KRT19 are the most reliable markers for the human bulge (Michel et al., 1996; Liu et al., 2003; Orringer et al., 2006). KRT15 promoter activity is restricted to the bulge region of adult mouse HFs, whereas KRT15 protein is expressed in the bulge region as well as in the ORS of the upper HF and basal layer of interfollicular epidermis, in mice (Liu et al., 2003) and humans (Orringer et al., 2006). These observations suggest that KRT15 protein expression persists in differentiated cells after KRT15 mRNA production is turned off. KRT19 is an intracellular protein expressed in $\left[{ }^{3} \mathrm{H}\right]$-thymidine label-retaining cells of murine HF bulge cells (Michel et al., 1996), and in the bulge and ORS of the lower part of the HF in humans (Orringer et al., 2006). However, since KRT15 and KRT19 detection requires cell permeabilization, these markers are not suitable for purification of intact cells. Recently, CD200, a cell surface protein that protects cells from autoimmune destruction in mouse (Rosenblum et al., 2006), has been identified as an additional specific marker of human bulge cells (Ohyama et al., 2006).

In addition to being structurally complex, the HF is a dynamic structure that undergoes life-long cycles of growth (anagen), regression (catagen) and resting (telogen) periods of its lower (or cycling) portion. In humans, HFs cycle independently from each other, and $\sim 90 \%$ of all human scalp HFs are in 
anagen (Krause \& Foitzik, 2006). In addition, nonbalding (occipital, i.e. back of the head) scalp HFs are not subject to age- or gender-related hair loss, thus ensuring a reliable supply of HFs throughout life.

Accumulating evidence suggests that impairment of SC function may be a major mediator of reduced capacity and vigor that invariably accompanies the passage of time in most organs (Edelberg \& Ballard, 2008). However, animal studies have shown that the effects of age on SC number and function vary among tissues. For instance, murine hematopoietic SC increase in number with age, but have an impaired ability to differentiate into lymphoid cells (Sudo et al., 2000). In contrast, aging does not alter mouse muscle SC number, but decreases muscle SC selfrenewing capacity and propensity to differentiate into myoblasts (Conboy et al., 2003). The impact of aging on skin SC functions remains largely unknown. A recent study has shown that the number of epidermal SCs (localized in the basal layer of the epidermis and distinct from HFSCS) is constant throughout life in mice (Giangreco et al., 2008). However, human skin keratinocytes (KCs) isolated from the epidermis of aged donors have decreased growing capacity in culture compared to cells originating from young donors (Barrandon \& Green, 1987). Thus, it remains unclear whether skin SCs are intrinsically modulated with aging or whether their diminished function reflects agemediated alterations of their environment (Zouboulis et al., 2008).

To gain insight into the mechanisms of human HFSC maintenance in healthy human skin and during aging, we have developed methodologies to isolate, count and profile gene expression in adult human bulge cells from young ( $<40$ years) and aged ( $>70$ years) healthy individuals. We could not detect any significant age-associated alterations in the number or marker expression level of scalp bulge cells in human skin. In parallel, we provide evidence that the hedgehog $(\mathrm{Hh})$ signaling pathway is activated in human bulge cells in vivo, and down-regulated in differentiated cells of the HF, both in young and aged skin. Finally, we show that activation of Hh signaling by lentivirusmediated overexpression of transcription factor Gli1 induces HFSC marker expression in human KCs in vitro. Taken together, these data indicate that aging does not significantly alter bulge cell number or expression of SC markers in human skin in vivo, and suggest a role for $\mathrm{Hh}$ signaling in maintaining expression of bulge cell markers in human skin throughout life.

\section{Results}

\section{Human bulge KCs, enriched in HFSCs, are defined

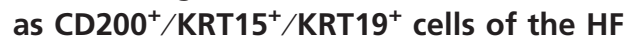

Scalp skin sections were analyzed by immunohistochemistry to localize CD200, KRT15 and KRT19 protein expression. Consistent with previous reports (Ohyama et al., 2006; Kloepper et al., 2008), we observed that CD200+ cells of human HFs are localized in the ORS, between the SG and the insertion of the AP muscle, the area known as human bulge (Fig. 1A). In addition, immunostaining of consecutive sections indicated that CD200 cells also express KRT15 and KRT19 proteins, albeit KRT15 and KRT19 protein expression extends above and below the bulge, respectively (Fig. 1B). As summarized in Fig. 1C, human bulge $\mathrm{KCs}$, enriched in HFSCs, can be identified as CD200 $/ \mathrm{KRT}^{+} 5^{+}$/ KRT19+ cells of the HF.

\section{Isolation and characterization of human bulge cells in young human skin}

Fresh scalp biopsies were obtained from individuals aged 40 years or under ('young'), and bulge cells were isolated based on selective cell surface expression of CD200. As CD200 is expressed in various cells in the dermal endothelium as well as in bulge cells (see Fig. 1B), we first isolated whole HFs from fresh skin biopsies (see Methods). Hematoxylin staining of isolated HFs showed that all cell layers were intact and separated from the surrounding dermal tissue, interfollicular epidermis and SGS (Supporting Fig. S1). Total HF KCs were dissociated by trypsin, and $\mathrm{CD} \mathrm{OO}^{+}$cells were purified by magnetic immunosorting using anti-CD200 antibody as described in Methods. Transcript levels of HFSC markers were quantified in $\mathrm{CD}_{200^{+}}$(bulge KCs) and $\mathrm{CD}^{2} \mathrm{OO}^{-}$(differentiated HF KCs) cell populations by quantitative real-time reverse-transcription polymerase chain reaction (Q-PCR). CD200 mRNA levels were 7.7-fold higher in CD200+ vs. CD200 ${ }^{-} \mathrm{HF}$ cells $(n=6, P<0.05)$. KRT15 and KRT19 mRNA levels were 5.9- and 50-fold higher, respectively, in CD200 compared to CD200 ${ }^{-}$cells of the HF $(n=6, P<0.05)$ (Fig. 2A). In contrast, transcripts for transglutaminase 1 [TGM1, enzyme involved in cornified-envelope formation and present in the inner root sheath of human HFs (Commo \& Bernard, 1997)] were more highly expressed in differentiated HF KCs compared to bulge cells (Fig. 2B, $n=3, P=0.022$ ). Taken together, these data demonstrate that dissection-combined CD200 selection yields a highly enriched human scalp bulge cell population, defined as $\mathrm{CD}^{2} 00^{+} / \mathrm{K} 15^{+} / \mathrm{K} 19^{+}$cells of the HF.

\section{Additional markers of young human bulge KCs}

Several gene products have been identified (mostly from microarray analyses) as selectively expressed in murine or human bulge cells, compared to differentiated HF KCs. These gene products include CD34 (Morris et al., 2004; Tumbar et al., 2004), follistatin (Ohyama et al., 2006), Dkk3 (dickkopf homolog 3) (Morris et al., 2004; Tumbar et al., 2004), Tcf3 (Blanpain et al., 2004; Tumbar et al., 2004), Gas1 (growth arrest-specific 1) (Blanpain et al., 2004; Tumbar et al., 2004), CCN2/CTGF (connective tissue growth factor) (Tumbar et al., 2004), S100A4 (Tumbar et al., 2004), Nestin (Li et al., 2003) and Bmi-1 (Claudinot et al., 2005). We used immunostaining or Q-PCR to determine the relative expression of these gene products in human bulge cells, compared to differentiated HF KCs.

CD34 and follistatin expression were studied by immunohistochemistry. As previously reported (Poblet et al., 1994, 2006; Ohyama et al., 2006; Orringer et al., 2006; Kloepper et al., 


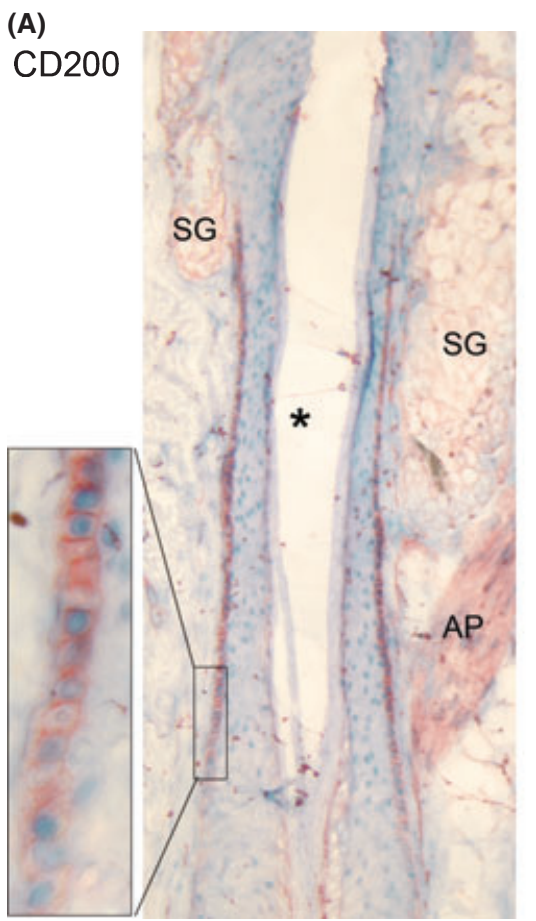

\section{$\begin{array}{lll}\text { (B) KRT15 } \quad \text { CD200 } \quad \text { KRT19 } & \end{array}$}

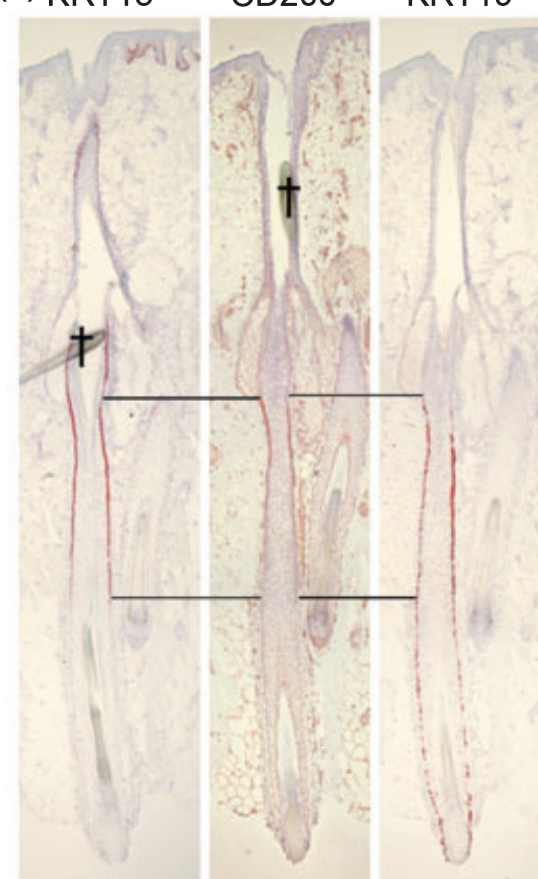

(C)

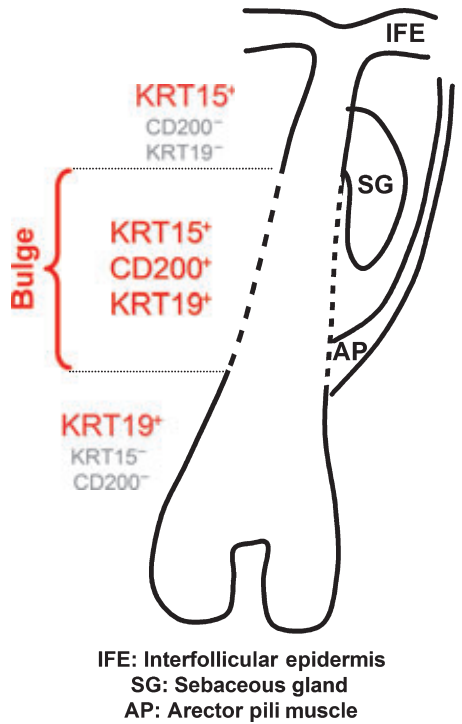

Fig. 1 Characterization of human bulge cell markers. (A) CD200+ cells were stained in red by immunohistochemistry (magnification $=100 \times$ ). Black rectangle identifies boundaries of $400 x$ magnification shown in left inset. Positive cells are located in the outer root sheath of the hair follicle $(\mathrm{HF})$, between insertions of sebaceous glands (SG) and arrector pili muscle (AP). Asterisk shows lumen of the HF (hair shaft was lost during staining). (B) Consecutive sections of human scalp skin biopsies from young individuals were stained for KRT15, CD200, and KRT19 by immunohistochemistry. Upper and lower limits of CD200 positive staining superimpose with those of KRT19 and KRT15 respectively (highlighted by black lines). Daggers indicate hair shafts remnants. (C) Schematic representation of localization of protein used as human bulge cell markers. Bulge cells are

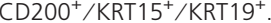

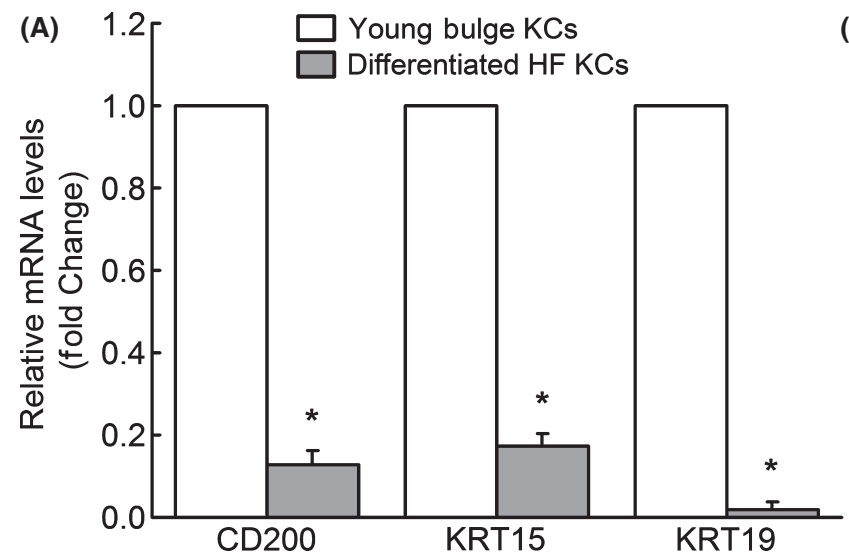

(B)

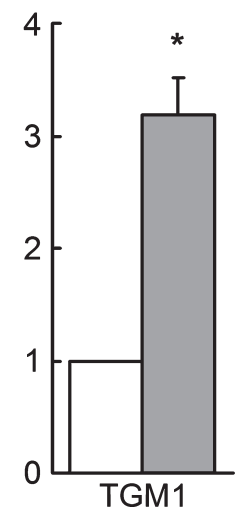

Fig. 2 Characterization of isolated human bulge cells from young human skin. (A) CD200, KRT15 and KRT19 mRNA levels were measured by Q-PCR on CD200' (bulge) and CD200- (differentiated) cells of the hair follicle (HF) in young $(<40$ years) individuals. $N=6$ : $* P<0.05$. (B) Transglutaminase 1 (TGM1) mRNA levels in same cell populations. $N=3 ; P=0.022$. 
2008), we observed that CD34 immunoreactivity was not detected in human bulge $\mathrm{KCs}$, but in the lower part of the ORS (corresponding to the cycling portion of the HF) as well as dermal cells surrounding the HF (Fig. 3A). Q-PCR analysis of

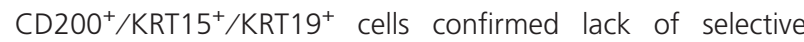
expression of CD34 transcripts in human bulge KCs (data not shown). In parallel, we observed that follistatin was expressed in the ORS of human HFs and in lower parts of rete ridges of inter- follicular epidermis (Fig. 3B). These data indicate that follistatin protein expression extends beyond the bulge, as observed previously (Ohyama et al., 2006), and is therefore not a specific protein marker for HFSCs.

With the exception of Bmi-1, Dkk3, Tcf3, Nestin, Gas1, CCN2 and S100A4 transcripts were selectively expressed in young human bulge cells, compared to differentiated HF KCs (respectively 12.2-, 2.3-, 1.7-, 5.3-, 3.6- and 1.9-fold higher in CD200+
Fig. 3 Additional markers of young human bulge keratinocytes. (A, B) Frozen scalp skin sections from young individuals were immunostained for CD34 (A) and follistatin (B). Original magnification $=100 \times$. Black rectangle indicates location of left inset (magnification 400x). Black arrows represent upper and lower limits of bulge area. Representative of at least four individuals. (C) Quantitative expression of gene transcripts for various potential hair follicle (HF) stem cell markers in bulge $\left(\mathrm{CD} 2 \mathrm{O}^{+}\right)$and differentiated $\left(\mathrm{CD} 200^{-}\right)$ cells of the HF in young human skin. $N=6$; ${ }^{*} P<0.05$; NS = not significant vs. bulge cells. Gas1, EGFR, CCN2 and S100A4 are represented in separate bar graphs to account for higher basal expression levels.
(A)

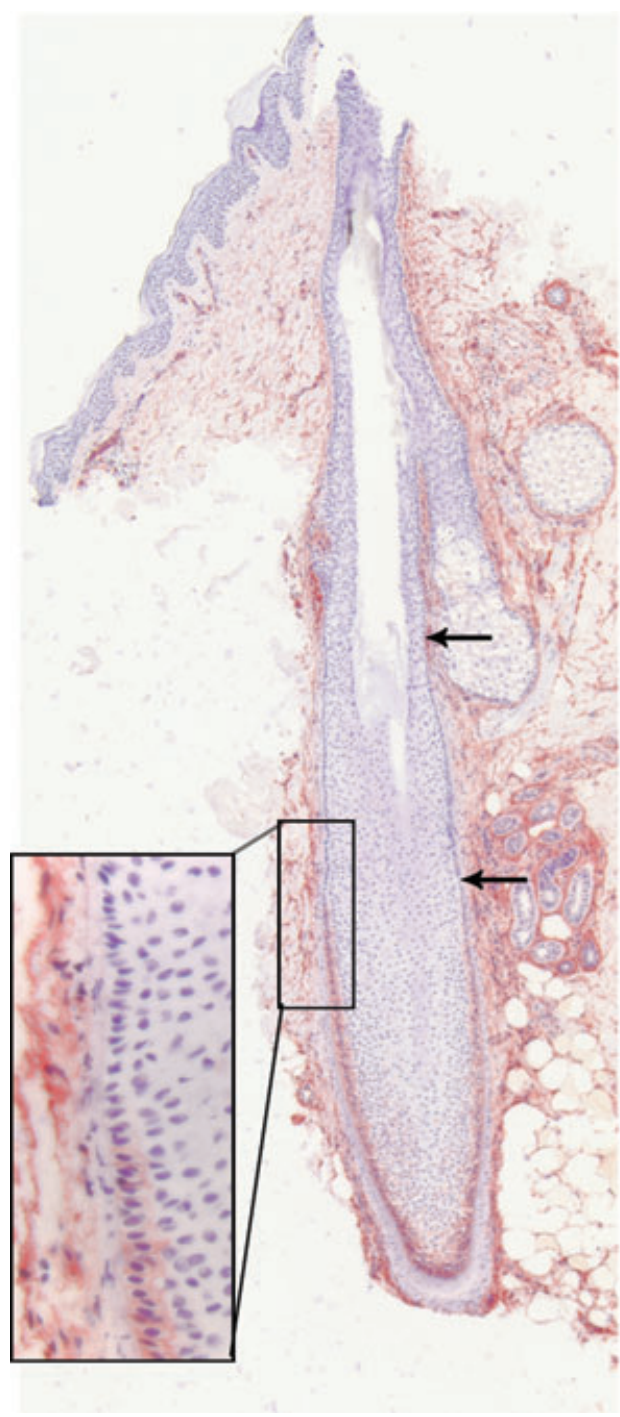

\section{CD34}

(B)
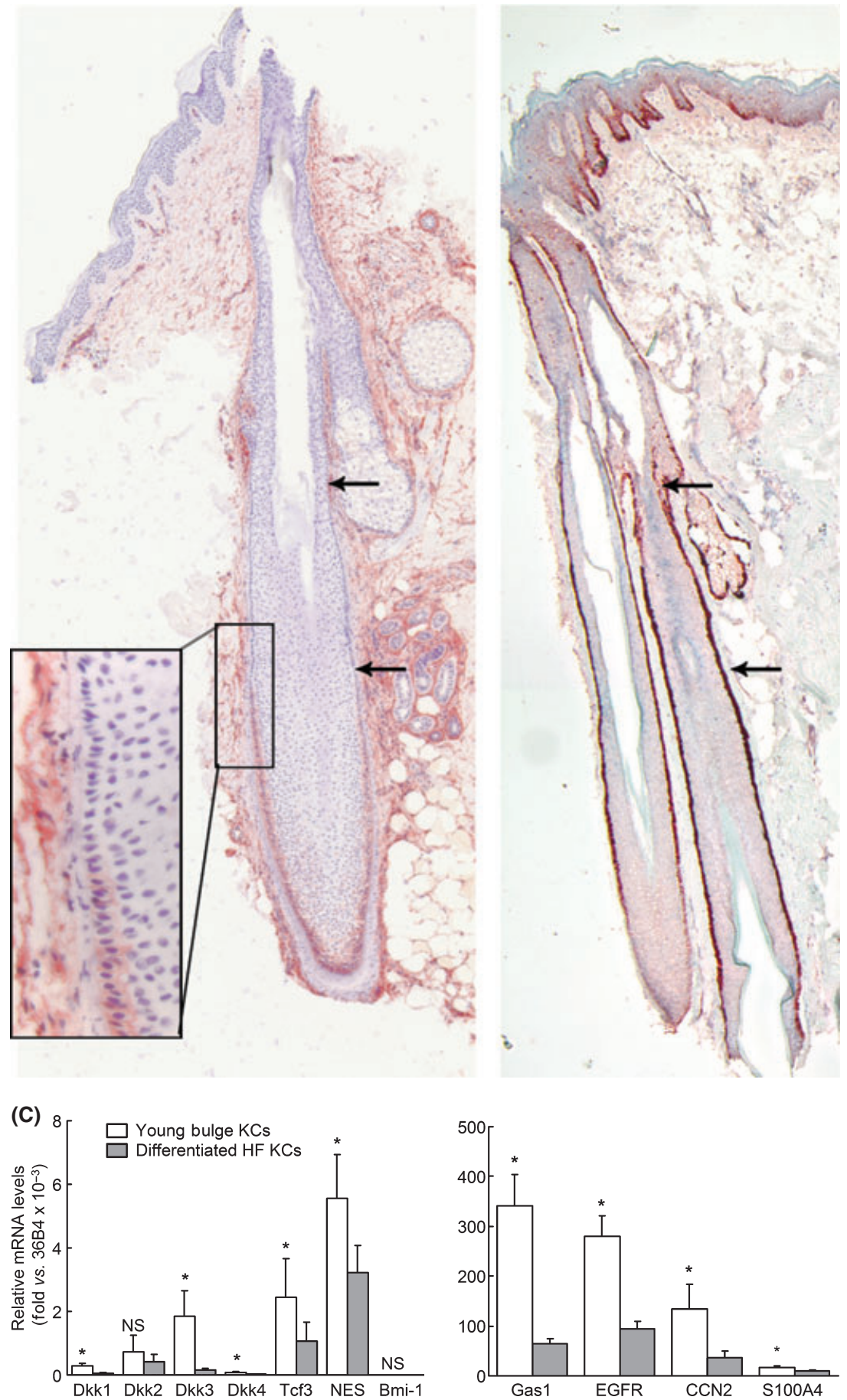
vs. CD200- cells in young individuals, $n=6, P<0.05$, Fig. $3 C$ ). In addition, we found that Dkk1 and Dkk4, but not Dkk2, were also selectively expressed in young human bulge cells compared to differentiated HF KCs, although barely detectable by Q-PCR (Fig. 3C). Additional screening revealed that epidermal growth factor receptor (EGFR) was also selectively expressed in young human bulge cells compared to differentiated HF KCs (3.0 \pm 0.25 fold, $n=6, P=0.0001)$ (Fig. 3C).

\section{Aging does not alter bulge cell number in human skin}

To assess the effects of aging on human bulge cell number, fresh scalp biopsies were obtained from the nonbalding scalp of 15 young and 13 aged individuals, and HFs were plucked and counted. HF density did not significantly differ between aged and young scalp skin (Fig. 4A, $P=0.080, n=15$ and 13 for young and aged, respectively). Noteworthily, we did not observe any gender-associated alteration of HF numbers (young: seven women, eight men; aged: seven women, six men) (data not shown). As we found the number of $\mathrm{CD}^{2} \mathrm{O}^{+}$cells per $4 \mathrm{~mm}$ biopsies too small to be reliably counted, we measured doublestranded DNA (dsDNA) content as a surrogate for cell number. As shown on Fig. 4B, dsDNA measured in these conditions correlates with cell number, as assessed with cultured KCS (measurements in triplicates, $R^{2}=0.9991$ ). In addition, we observed that aging did not significantly alter the number of

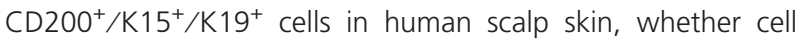
number was normalized per biopsy (Fig. 4C) or per HF (Fig. 4D) ( $n=5-6, P=0.41$ and 0.44 , respectively). Overall, our data indicate that skin aging does not significantly alter the number of bulge cells in human scalp skin in vivo.

\section{Aging does not alter bulge marker expression in human skin}

To evaluate the effects of aging on HFSCs, HFSC marker expression was determined in fresh scalp skin biopsies obtained from individuals aged 70 years and above ('aged'). Compared to young scalp skin (Fig. 1), we observed similar protein expression and localization of HFSC marker protein expression by immunochemistry: cells of human HFs, localized in the ORS, between the SG and the insertion of the AP muscle (bulge area) were all positive for CD200, KRT15 and KRT19 (not shown). Correspondingly, Q-PCR analysis of $\mathrm{CD}_{200^{+}}$and $\mathrm{CD}^{200^{-}} \mathrm{KCS}$ from aged HFs showed that expression of HFSC markers CD200 and KRT19 was similar in aged vs. young HFSCs (Fig. 5A). KRT15 mRNA expression was slightly higher (1.9-fold) in aged vs. young bulge $\mathrm{KCs}(n=6, P=0.048)$. Overall, these data indicate that human skin aging is not associated with alteration of the bulge
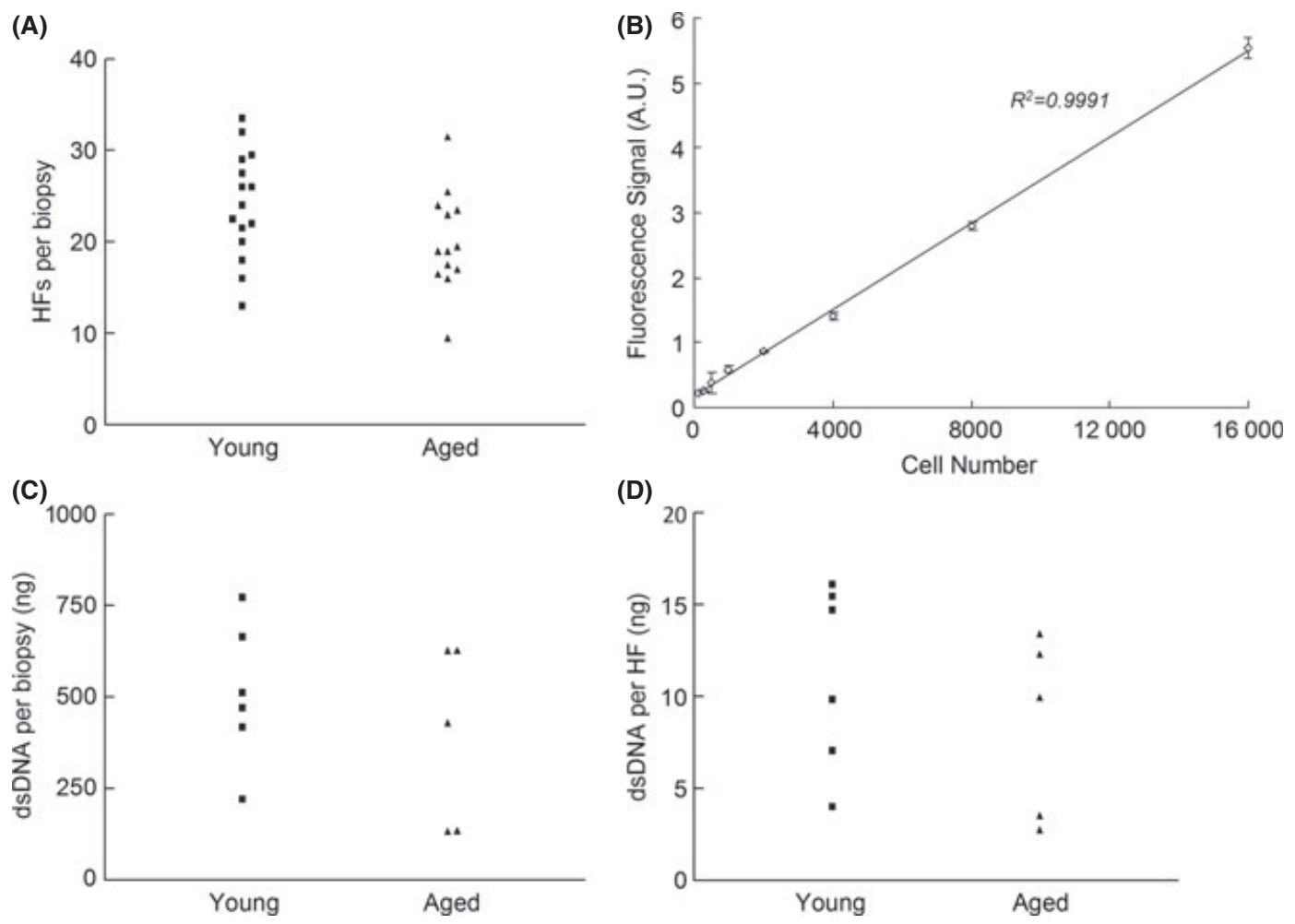

Fig. 4 Effect of aging on hair follicle (HF) and bulge cell number in human skin in vivo. Hair follicles were isolated from nonbalding scalp skin samples from young (< 40 years) and aged (> 70 years) individuals, and counted. (A) Number of HFs per biopsy, $N=13$ (aged) and 15 (young). (B) Validation of double-stranded DNA (dsDNA) measurement assay linearity with cultured keratinocytes: fluorescence signal correlates with cell number. Measurements in triplicates, $R^{2}=0.9991 .(C, D)$ dsDNA was quantified as surrogate for cell number, and normalized per biopsy (B), or per $\mathrm{HF}(C) . N=6-5$, each measurement was done in duplicate. Differences between young and aged were not significant (see text). 

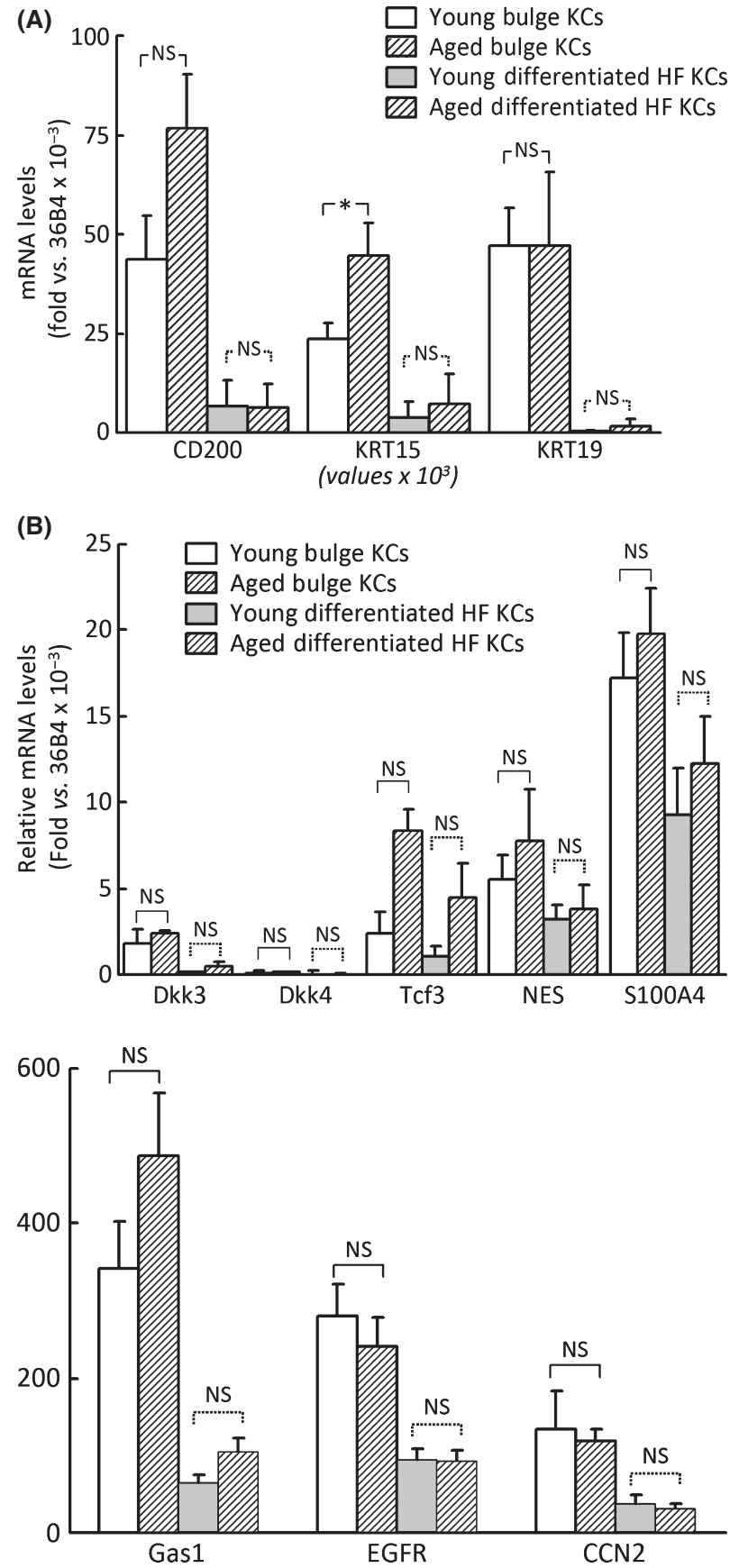

Fig. 5 Aging does not alter bulge marker expression in human skin. Total RNA from bulge $\left(C D 200^{+}\right)$and differentiated $\left(C D 200^{-}\right)$cells of the hair follicle (HF) were isolated from scalp skin biopsies of young ( $<40$ years) and aged (> 70 years) individuals, and analyzed by Q-PCR for human HF stem cell markers. (A) Quantitative expression of CD200, KRT15 and KRT19 human bulge cell markers. (B) Direct comparison of gene transcript levels of various potential additional bulge cell markers between young and aged individuals. Gas1, EGFR and CCN2 are represented in separate bar graphs to account for higher expression levels. $N=6$; ${ }^{\star} P<0.05$; NS = not significant vs. young counterpart.

compartment size, or level of expression of CD200, KRT15, and KRT19 in bulge cells.

Further Q-PCR analyses of aged bulge KCs indicated selective expression of the same SC markers expressed in bulge cells from young skin (shown in Fig. 3C). Taken together, these data suggest that human HFSCs are characterized by increased expression of Dkk3, Dkk4, Tcf3, S100A4, Gas1, EGFR, and CCN2, compared to differentiated HF KCs in young and aged human skin in vivo (Fig. 5B).

\section{Cyclin-dependant kinase inhibitors are not altered in aged human HF bulge $\mathrm{KCs}$}

Cellular proliferation is governed by cyclin-dependent kinases (CDKs), which associate with cyclins to drive cells through the cell cycle. CDK activities are negatively regulated by CDK inhibitors (Sherr \& Roberts, 1999; Shapiro, 2006). CDK inhibitors are, at least in mouse, potent blockers of adult SC proliferation in various tissues. For instance, the product of the $p 16^{\text {INK4a }}$ gene is transcriptionally upregulated in forebrain, pancreas, and hematopoietic SCs of older mice (Janzen et al., 2006; Krishnamurthy et al., 2006; Molofsky et al., 2006), resulting in decline of SC proliferation capacities in these organs. The product of the p16 ${ }^{\text {INK4a }}$ gene has also been shown to be increased in epidermal and dermal compartments of human skin with aging (Ressler et al., 2006). Other CDK inhibitors have been shown to similarly regulate adult SC proliferation potential in other mouse tissues (Boyer \& Cheng, 2008). To evaluate whether HFSCs are similarly regulated by natural aging in humans, we quantified CDK inhibitors gene products in bulge KCs of young and aged individuals. Our results show no significant difference in the expression of $\mathrm{p} 15^{\mathrm{INK} 4 \mathrm{~b}}(P=0.166), \mathrm{p} 16^{\mathrm{INK} 4 \mathrm{a}} / \mathrm{p} 19^{\mathrm{INK} 4 \mathrm{~d}}(P=0.095)$, p21 ${ }^{\text {Cip1/Waf1 }}(P=0.393)$, or p27 Kip1 $(P=0.225)$ between bulge KCs of young and aged individuals ( $n=6$ per group) (Supporting Fig. S2).

\section{Hedgehog pathway components are selectively expressed in human bulge cells relative to differentiated HF KCs}

In a variety of tissues, several developmental pathways govern SC maintenance, differentiation and lineage commitment, including Notch, Wnt/ $\beta$-catenin, Hh, Bmi-1 and p63 pathways (Katoh \& Katoh, 2006; Ross \& Li, 2006). We therefore quantified transcript levels of components and target genes of potentially relevant developmental pathways in human bulge and differentiated HF KCs from young individuals. Our results revealed that, among the tested pathways, many components and target genes of the Hh pathway were upregulated in bulge cells compared to differentiated HF KCs. These gene products include the transmembrane receptors patched (Ptch)- 1 and smoothened (Smo), and the downstream transcription factors Gli1, Gli2, and Gli3 (Fig. 6A). In contrast, we found that expression of Hhip (Hh interacting protein), an antagonist of the Hh pathway (Chuang \& McMahon, 1999; Olsen et al., 2004), was not significantly different in bulge cells vs. differentiated HF KCs ( $n=6, P=0.467)$.

The same approach was used to investigate developmental pathways in HFSCs from aged individuals. Analysis of gene expression indicated that $\mathrm{Hh}$ signaling pathway is also activated 

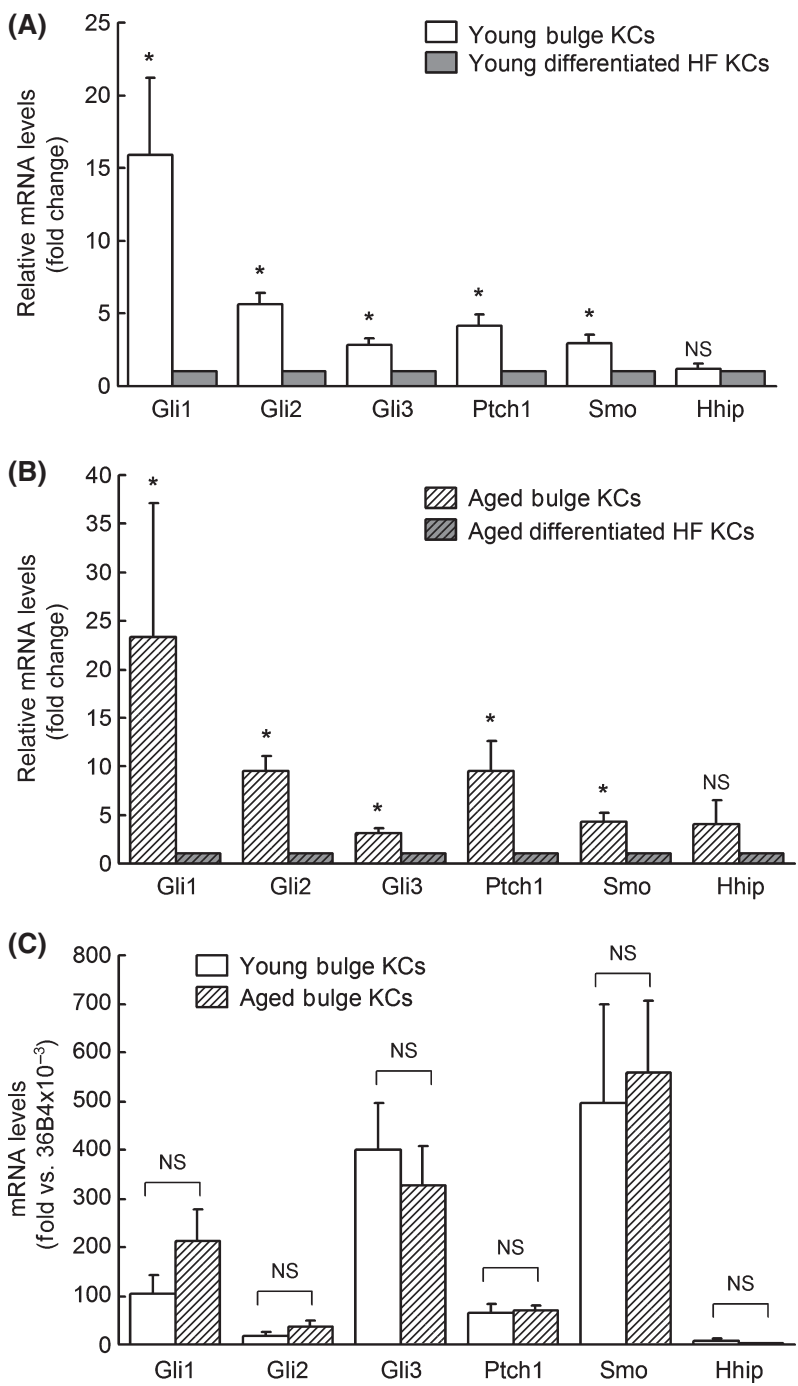

Fig. 6 Hedgehog (Hh) pathway components are selectively expressed in human bulge cells vs. differentiated hair follicle (HF) keratinocytes (KCs). Transcript levels of $\mathrm{Hh}$ pathway components and target genes were quantified by Q-PCR in bulge $\left(C D 200^{+}\right)$and differentiated $\left(C D 200^{-}\right)$cells of human HFs. $N=6$; $(\mathrm{A})$ young and $(\mathrm{B})$ aged individuals. ${ }^{*} P<0.05$; NS $=$ not significant vs. differentiated HF KCs. (C) Quantitative expression of levels of Hh pathway components and target genes transcripts in bulge cells of young and aged individuals. NS = not significant vs. young counterpart.

in aged bulge KCs, compared to differentiated HF KCs. Expression of Gli1 and Ptch1 [Hh responsive genes (Ingham \& McMahon, 2001)], Gli2, Gli3, and Smo, but not Hhip, were significantly elevated (Fig. 6B). Direct comparison of bulge KCs from young and aged human skin indicated that the Hh pathway component and target genes were expressed at similar levels (Fig. 6C). No statistical difference was observed in the expression of Gli1 $(P=0.218)$, Gli2 $(P=0.588), \quad$ Gli3 $(P=0.527)$, Ptch1 $(P=0.541)$, Smo $(P=0.563)$, or Hhip ( $P=0.582$ ) between young and aged bulge cells $(n=6)$.

As shown in Fig. 7, the Hh transmembrane receptor and target gene product Ptch is preferentially expressed in the bulge area of human HFs (ORS below the SG and above the insertion of the AP muscle). Double immuno-fluorescence staining confirmed co-expression of Ptch and CD200 within HF bulge KCS (Fig. 7B). Taken together, these data indicate that the $\mathrm{Hh}$ pathway is preferentially activated in HFSCS, relative to differentiated $\mathrm{HF} \mathrm{KCS}$, and that selective Hh pathway expression is not altered with aging.

\section{Hedgehog signaling pathway maintains the HFSC phenotype in human keratinocytes}

To gain insight into the role of the Hh pathway in human bulge cells, we overexpressed Gli1 in the NTert-2G immortalized KC cell line (referred to as NTert-Gli1). Gli1 protein was detected in the majority of NTert-Gli1 cells, but not in NTert-GFP controls (Fig. 8A): immunofluorescence signal was primarily detected in perinuclear areas, and as punctuate staining in cell nuclei (Fig. 8A). Q-PCR analysis indicated that basal Gli1 expression levels were near Q-PCR detection limits in NTert-GFP control $\mathrm{KCS}$, whereas Gli1 was readily detected $\left(81 \times 10^{-3}\right.$ fold the levels of housekeeping gene 36B4) in NTert-Gli1 KCs (Fig. 8B), with Gli1 transcript levels similar to those measured in scalp skin in vivo $\left(104 \times 10^{-3}\right.$-fold the levels of 36B4 in young bulge cells, Fig. 6C). Induction of the $\mathrm{Hh}$ target gene Patch1 (2.3-fold, $P<0.05)$ indicated that Gli1 was active in NTert-Gli1 KCS (Fig. 8B). Interestingly, further analyses showed that activation of Hh pathway increased expression of the human HFSC markers KRT15 (2.4-fold), KRT19 (detected from undetected), and Gas1 (2.4-fold vs. GFP controls) in human KCs $(n=3, P<0.05)$ (Fig. 8B). However, Gli1 overexpression did not significantly alter expression of CD200, which was near Q-PCR detection limits in these cells (Fig. 8B). These results show that Hh pathway activation promotes expression of characteristic HFSC markers in human skin $\mathrm{KCs}$.

\section{Discussion}

The present study was designed to evaluate the effects of aging on human HFSC characteristics in vivo. We demonstrate that aging does not significantly alter total number of human scalp skin HFs, tissue distribution of SC marker proteins (CD200, KRT15, KRT19), SC mRNA expression per cell (i.e. normalized to housekeeping gene), bulge cell dsDNA content per skin surface area, or bulge cell dsDNA content per HF. In addition, we identify Hh signaling pathway as being preferentially activated in human HF bulge cells, compared to differentiated HF cells, both in young and aged human skin in vivo. In vitro experiments revealed that increased expression of Gli1 induces expression of several HFSC markers in human KCs, and suggest a role for $\mathrm{Hh}$ signaling in maintaining bulge cell phenotype in human skin.

Putative HFSCs have been identified as quiescent cells in vivo by label-retaining cell studies (Cotsarelis et al., 1990; Ohyama et al., 2006), and have been localized in the bulge area of human HFs, i.e. the ORS located between the insertion of the AP muscle and SGs (Ohyama et al., 2006). Here, we describe a dissectioncombined CD200 selection of bulge cells from fresh human skin, 
(A)
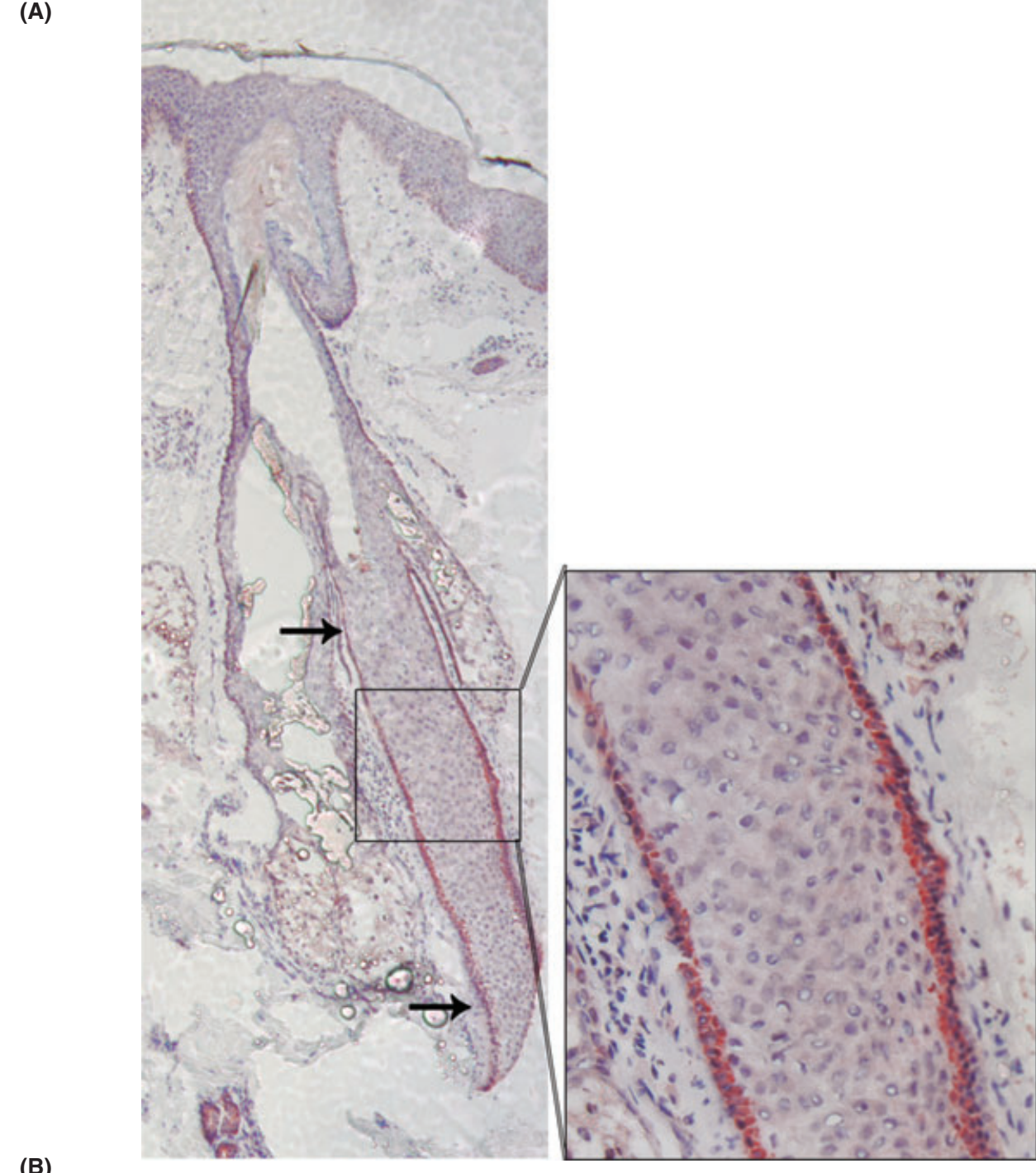

(B)

\section{CD200}

Ptch
Overlay

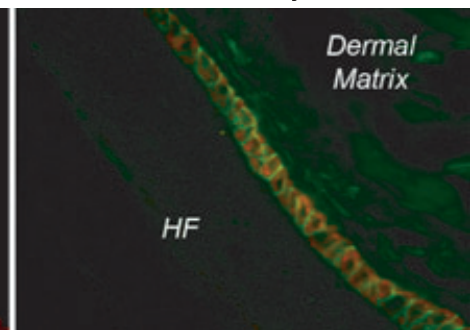

Fig. 7 The hedgehog transmembrane receptor and target gene product Ptch is expressed in CD200 ${ }^{+}$cells of the bulge area of human hair follicles. (A, B) Ptch protein expression was stained by immunohistochemistry 100× magnification (A). Black rectangle in A identifies boundaries of $200 \times$ magnification shown in B. (C) Double immunofluorescence staining of human bulge area. Human scalp sections were stained with CD200 (green) and Ptch (red). Overlay shows that Ptch is expressed by $C D 200^{+}$cells of the human bulge area. Magnification $=400 \times$. Representative of at least three individuals.

and show that the isolated cells express several HFSC markers, i.e. CD200, KRT15, KRT19, Dkk3, and Tcf3. It should be noted that bulge localization, which is highlighted by positive expression of CD200 protein and mRNA, by itself is not sufficient to identify these cells as true SCs. Mouse and rat studies have previously shown that bulge-localized cells were all SCs, based on their ability to self-renew in vitro and to generate all skin epithelial lineages (epidermis, HFs, sebaceous and sweat glands) when isolated and grafted onto nude mice (Blanpain et al., 2004; Claudinot et al., 2005; Fuchs, 2008). However, similar experiments have yet to be carried out with human bulge cells to determine the homogeneity of the $\mathrm{CD}_{2} \mathrm{OO}^{+}$cell population. 

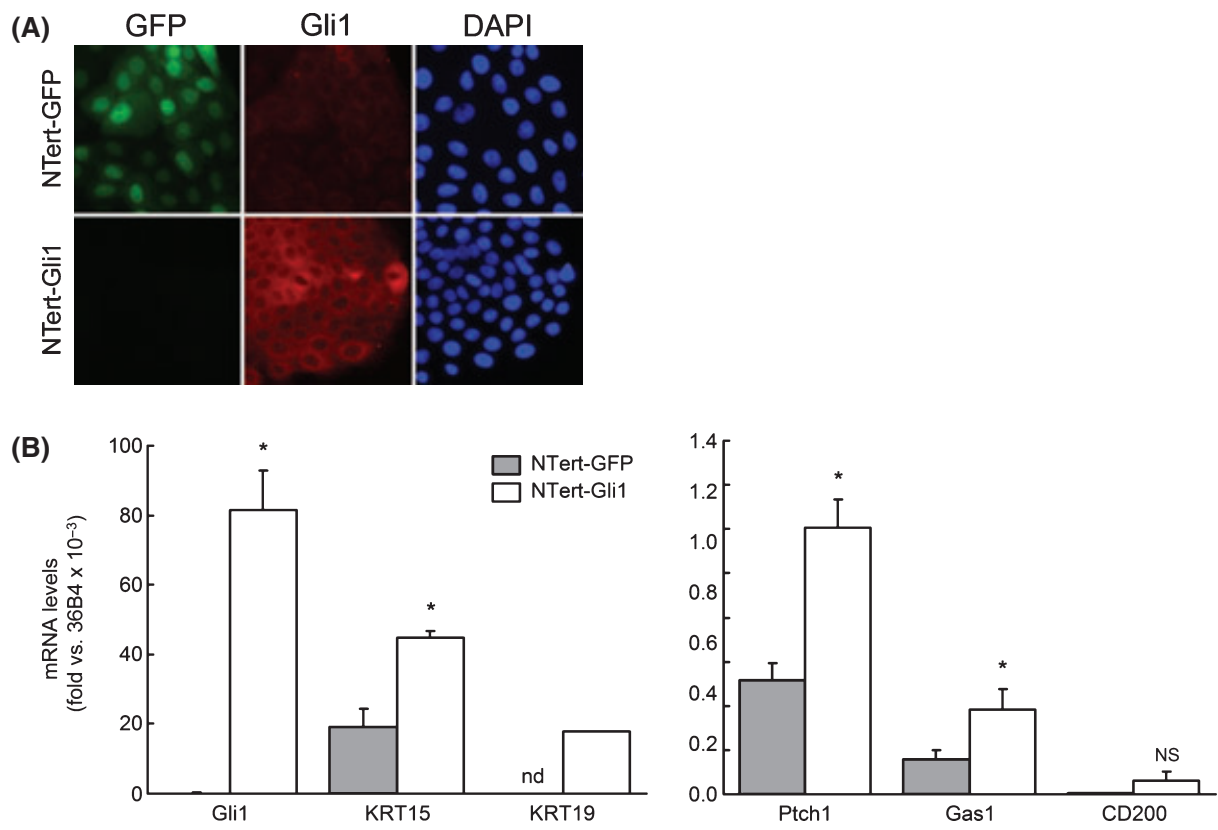

Fig. 8 Overexpression of Gli1 increases human hair follicle stem cell markers in human keratinocytes (KCs). Gli1 or GFP (negative control) were stably overexpressed in NTert-2G KCs. Gli1 overexpression was confirmed by immunofluorescence (A) and mRNA quantification (B). Stem cell marker gene transcripts were quantified by Q-PCR in NTert-GFP and NTert-Gli1 KCs (B). $N=3$; ${ }^{*} P<0.05$; NS = non significant vs. NTert-GFP. ND = not detected.

Age-related alterations of skin structure and function, which include skin atrophy, loss of elasticity and tone, and impaired wound healing (Rittié et al., 2010), are consistent with the concept of age-related decline of skin HFSC functions. Here, we were unable to show any statistically significant effects of aging on (i) HF count, (ii) bulge cell dsDNA content per skin surface area, (iii) bulge cell dsDNA content per HF, (iv) CD200 bulge cell mRNA expression per cell (i.e. normalized to housekeeping gene), (v) tissue distribution of SC marker proteins (CD200, KRT15, KRT19) relative to morphological limits of the human bulge. These results suggest that aging has no significant effects on the size of the bulge compartment in human scalp skin in vivo. It should be noted that there were substantial overlaps between young and aged groups in the values of HF density and bulge cell dsDNA content per HF (Fig. 4). Although the mean values in the aged group were modestly lower, the two groups were not statistically different. While a much larger sample size (112 subjects estimated by power analysis) might have revealed a statistical difference, the biological importance of a subtle decrease remains to be clarified. Nevertheless, it is possible that age-associated changes do exist, but are too subtle to be measured by our analytical techniques. In addition, our data do not rule out a possible age-related decrease in self-renewal capacity of HFSCs, or in the capacity of HFSCs to generate optimally functioning transient amplifying cells, which are characterized by high proliferation and differentiation capacity. Alternatively, potential age-related decline of HFSC clonogenic properties could be associated with extrinsic signals from the SC niche, as suggested in the epidermis and other tissues (Zouboulis et al., 2008). Reported age-related alterations of dermal structure and function (Rittié et al., 2010) are consistent with this view.
Additional ex vivo functional studies are required to test these possibilities.

Several Hh signaling pathway components were selectively expressed in bulge vs. differentiated KCs. Among these, were transcription factors Gli1, 2, and 3, and the pathway receptors Ptch1 and Smo. Gli1 and Ptch1 are Hh target genes and their expression indicates Hh pathway activity (Ingham \& McMahon, 2001). Interestingly, Gas1, which is preferentially expressed in young and aged bulge cells compared to differentiated HF KCS (Fig. 4B), prevents cell cycling by blocking entry to $S$ phase. In addition, Gas1, which is a GPI-anchored plasma membrane protein, has been shown to facilitate $\mathrm{Hh}$ ligand binding to Ptch1 receptor, thereby increasing $\mathrm{Hh}$ signaling activity in presence of low concentration of ligand (Martinelli \& Fan, 2007; Seppala et al., 2007). In parallel, we found that Hhip, a Hh ligand-binding protein antagonist of the pathway (Chuang \& McMahon, 1999; Olsen et al., 2004), was expressed at low levels throughout the HF. Altogether, these observations strongly support Hh pathway activation in human bulge cells.

Consistent with our findings that $\mathrm{Hh}$ signaling is activated in bulge cells of human HFs, Ghali et al. (1999) have shown immunoreactivity for Gli1 in bulge KCs and in a subpopulation of mesenchymal cells in the vicinity of the HF bulge. We were unable to detect Gli1 protein in skin samples by immunohistochemistry using three different antibodies. Additional studies have reported signs of activation of $\mathrm{Hh}$ signaling in murine bulge cells, including positive Gli2 immunostaining in the permanent portion of the follicle below the SGs (Niemann et al., 2003), as well as in $\mathrm{CD} 4^{+} \mathrm{Lgr5}^{-}$upper bulge KCs and $\mathrm{CD}^{-} 4^{-} \mathrm{Lrg}^{+}$secondary hair germ progenitor cells (Jaks et al., 2008). 
Given the apparent activation of the Hh pathway in HFSCs, identification of the source of Hh ligands is of interest. Despite multiple attempts, we were unable to identify Hh ligand expressing cells in HF KCs. The two ligands Sonic and Indian Hh (Shh and Ihh, respectively) could not be reliably detected in HF KCs by Q-PCR. A possible explanation for this observation is that $\mathrm{Hh}$ ligand(s) is produced by cells located in areas surrounding HFs. To our knowledge, Hh ligand expression has not been extensively studied in human skin. In contrast, animal studies have shown that Shh is primarily expressed in the hair bulb (terminal lower part of the HF) and epidermis (Iseki et al., 1996), whereas Ihh is expressed in sebocytes (Niemann et al., 2003). Similar studies in human skin are necessary to identify the source of $\mathrm{Hh}$ ligands. Alternatively, Gli expression could be the result of noncanonical Hh signaling activation, as Gli can be induced by the Ras or TGF- $\beta$ pathways (Athar et al., 2006). Consistent with the later hypothesis, we show that CTGF/CCN2, a direct target of TGF- $\beta$ (Grotendorst et al., 1996; Secker et al., 2008), is selectively elevated in young and aged bulge cells, compared to differentiated HF KCs (Fig. 5B). Moreover, we show that Gli3 as well as Gli1 are expressed in bulge cells at relatively high levels (Fig. 6C). In the presence of $\mathrm{Hh}$ ligand, processed $\mathrm{Gli3}$ is generally described as a transcriptional repressor of $\mathrm{Hh}$ targets (Ingham \& McMahon, 2001). However, it has been suggested that, during development, an activating form of Gli3 could induce Hh targets such as Gli1 (Ingham \& McMahon, 2001). Detailed analyses are required to determine the basis of $\mathrm{Hh}$ pathway activation in human bulge cells.

We demonstrate that overexpression of Gli1 in human KCs increases expression of several markers of human bulge SCS including KRT15, KRT19 and Gas1. These results confirm a previous report by Kasper et al. (2006), which demonstrated upregulation of KRT15 and 19 in a similar culture model. Importantly, the same group recently reported that Gli1 overexpression in immortalized KCs triggers additional SC characteristics including compact colony formation, which is associated with repressed extracellular signal-regulated kinase basal activity, even in the presence of retrovirus-mediated EGFR overexpression (Neill et al., 2008). Although overexpression of Gli1 recapitulates some of the HFSC characteristics, it is unlikely that Gli1 overexpression alone could induce pluripotency in KCs. The extent to which Hh cooperates with other factors in the maintenance of HFSC phenotype is an important area for further study.

A key role of $\mathrm{Hh}$ signaling in promoting some bulge $\mathrm{KCs^{ \prime }}$ characteristics is in agreement with published animal studies that have provided genetic evidence for a role of Hh signaling for maintenance of the HFSC niche. Indeed, it has been shown that disruption of $\mathrm{Hh}$ signaling in KRT14+ ${ }^{+}$cells (basal layer of epidermis and ORS of HF, including the bulge) results in depletion in the HFSC niche (Gritli-Linde et al., 2007). In addition, Vidal et al. (2005) reported that inactivation of the transcription factor Sox9 in skin depletes HFSCs, and is accompanied by thickening of the epidermis, and expression of epidermal markers, such as KRT1 and KRT10 in the HF. Interestingly, expression of Sox9 completely depends on Hh signaling during hair induction, and is restricted to the bulge compartment in adult mice (Vidal et al., 2005). These results suggest that $\mathrm{Hh}$ and/or Sox9 expression in HFSC s prevents KC differentiation toward the epidermal phenotype. Consistent with this view, recent studies in Drosophila suggest that $\mathrm{Hh}$ acts by blocking differentiation towards a default fate, thereby maintaining spatially selected cells in specific intermediate states (Vincent et al., 2008). It is plausible that, in skin, Hh signaling maintains spatially selected bulge cells in a quiescent state, blocking differentiation to epidermal KCs.

The role of Hh pathway in adult SC maintenance has been described in various other tissues, including mouse brain (Machold et al., 2003; Palma et al., 2005; Ninkovic et al., 2008), gut (Nielsen et al., 2004), liver (Sicklick et al., 2006), hematopoietic system (Trowbridge et al., 2006; Dierks et al., 2008; Zhao et al., 2009), and human mammary gland (Liu et al., 2006) and fetal epidermis (Adolphe et al., 2004; Zhou et al., 2006). To our knowledge, this study is the first to report sustained activity of Hh signaling in human HF bulge cells throughout life. Considering these findings together with evidence that disruption of $\mathrm{Hh}$ pathway components or effectors depletes the HFSC niche in animal models discussed above, one should carefully consider potential long-term deleterious outcomes of anti-cancer therapy that blocks Hh signaling (Rubin \& de Sauvage, 2006).

\section{Experimental procedures}

\section{Human subject description and tissue procurement}

All procedures involving human subjects were approved by the University of Michigan Institutional Review Board, and all subjects provided written informed consent prior to entering the study. Healthy volunteers aged $\leq 40$ ('young') and $\geq 70$ years ('aged') were enrolled with no racial/ethnic distinction. Two 4-mm fullthickness punch biopsies were obtained by trained medical personnel from the nonbalding region of the occipital scalp of healthy volunteers. For SC isolation, punch biopsies were placed into Hanks' Balanced Salt Solution (HBSS; Invitrogen, Carlsbad, CA, USA) containing penicillin and streptomycin (Invitrogen), and processed immediately. For immunohistochemistry experiments, skin biopsies were embedded in Tissue-Tek optimal cutting temperature (OCT) compound (Miles, Naperville, IL, USA), frozen in liquid nitrogen, and stored at $-80^{\circ} \mathrm{C}$ until processing.

\section{Total HF cell suspension preparation}

Fresh scalp skin biopsies were washed three times with HBSS, and external hairs were cut off with scissors. The epidermis containing the upper part of the HF infundibulum was removed using a sterile scalpel. The remaining tissue was incubated in $4 \mathrm{mg} \mathrm{mL}^{-1}$ dispase (Invitrogen) in HBSS overnight at $4{ }^{\circ} \mathrm{C}$. Individual HFs were plucked out of the tissue with forceps. In some cases, individual HFs were counted separately on two biopsies and the two numbers were averaged. Isolated HFs were rinsed in HBSS, incubated with $0.05 \%$ trypsin, 0.53 mm EDTA (Invitrogen) at $37^{\circ} \mathrm{C}$ for $30-45 \mathrm{~min}$. The HF containing solution was 
regularly pipetted up and down during digestion to promote cell dissociation. Total HF cells were peletted by centrifugation at $1000 \mathrm{~g}$ for $3 \mathrm{~min}$ and resuspended into magnetic assisted cell separation buffer (MACS buffer: PBS supplemented with $2 \mathrm{~mm}$ EDTA and $0.5 \%$ bovine serum albumin). Cell clumps and hair shafts were eliminated by filtration through a sterile $70 \mu \mathrm{m}$ pore cell strainer (BD Falcon/ThermoFisher Scientific, Pittsburgh, PA, USA), and total HF cells were resuspended into MACS buffer.

\section{Cell sorting}

The CD200+ (bulge) and CD200- (differentiated) HF KCs were separated using magnetic cell sorting with the indirect microbead MACS ${ }^{\circledR}$ system (Miltenyi Biotec, Bergisch Gladbach, Germany). Total HF cell suspensions were incubated with human IgGs (Sigma, St Louis, MO, USA) for 15 min at $4{ }^{\circ} \mathrm{C}$, and labeled with a mouse anti-CD200 antibody (AbD Serotec, Raleigh, NC, USA) at $4{ }^{\circ} \mathrm{C}$ for $15 \mathrm{~min}$. After three washes with MACS buffer, cells were incubated with microbeads coupled with rat antimouse $\operatorname{lgG}_{1}$ antibodies (Miltenyi Biotec) at $4{ }^{\circ} \mathrm{C}$ for $15 \mathrm{~min}$. After three washes with MACS buffer, cell suspension was loaded onto a column containing a ferromagnetic matrix exposed to the magnetic field of a permanent magnet. CD200cells were washed out of the column with three washes with MACS buffer, and CD200' cells were eluted from the column according to the manufacturer's instructions.

\section{Double-stranded DNA}

Double-stranded DNA quantification was used as a surrogate for evaluating cell number. Aliquots of total HF, CD200 ${ }^{+}$and $\mathrm{CD}^{2} 0^{-}$cell suspensions were lyzed in cell lysis buffer (RLT buffer of RNeasy kit; Qiagen, Chatsworth, CA, USA), and dsDNA was quantified using PicoGreen ${ }^{\circledR}$ dye (Invitrogen). Fluorescence signal was measured on an ABI 7300 (Applied Biosystems, Foster City, CA, USA) using the SybrGreen dye detection range, and converted into ng dsDNA using a standard curve ran in parallel. Assay linearity was confirmed with serial dilutions of dsDNA obtained from cultured KCs prepared in the same conditions. Results were normalized to number of HFs or skin area $(4 \mathrm{~mm}$ round biopsies i.e. $12.6 \mathrm{~mm}^{2}$ ).

\section{RNA extraction and CDNA preamplification}

Total RNA from CD200+ and CD200- cells were isolated in the presence of carrier RNA using an RNeasy Micro kit (Qiagen). Total RNA were reverse transcribed with random primers using a cDNA archive kit (Applied Biosystems). Complementary DNA was quantified using Oligogreen ${ }^{\circledR}$ dye (Invitrogen), and equal amounts of cDNA were preamplified using a Taqman ${ }^{\circledR}$ preamp master mix kit (Applied Biosystems) in a 14-cycle reaction using the same primers as the ones used for subsequent Q-PCR. For cultured cell samples, no cDNA preamplification was performed, and RNA extraction, quantification, and reverse transcription were performed as previously described (Rittié et al., 2008).

\section{Quantitative real-time reverse-transcription polymerase chain reaction}

CDNA was quantified by Q-PCR using Taqman PCR master-mix and validated primers-probes sets (Applied Biosystems). Efficiency and accuracy of preamplification reaction was verified in pilot studies by running identical samples preamplified and not, in parallel (not shown). Q-PCR results were normalized to the level of housekeeping gene 36B4 (internal control), and are presented as normalized fold change or fold vs. 36B4 $\times 1000$ $\left(=2^{-\Delta C T} \times 10^{3}\right)$, with $\Delta C T=C T_{36 B 4}-C_{\text {Target }}$.

\section{Immunohistochemistry}

OCT-embedded skin sections $(7 \mu \mathrm{m})$ were fixed in $2 \%$ paraformaldehyde or acetone/methanol (8:2, v/v), and immunohistochemistry was performed using a Link-Label IHC Detection System (Biogenex, San Ramon, CA, USA). Primary antibodies directed against CD200, KRT15, KRT19, Ptch, CD34 and follistatin were from AbD Serotec, Millipore (Billerica, MA, USA), Sigma, AbCam (Cambridge, MA, USA), Biogenex and R\&D Biosystems (Minneapolis, MN, USA) respectively. Slides were counterstained with hematoxylin (BioCare, Concord, CA, USA), and mounted with supermount medium (Biogenex). Digital images were captured on a Zeiss microscope. When needed, images were merged using the Canon Utilities PнотоSтITC 3.1 software. For immunocytochemistry, cells were seeded on Lab-Tek chambers (Nunc/ThermoFisher Scientific, Pittsburg, PA, USA) for 3 days, and immunostaining was performed as described elsewhere (Di Marcotullio et al., 2006) using anti-Gli1 antibody (sc-6152; Santa Cruz, Santa Cruz, CA, USA), biotinylated anti-goat antibodies (Vector Laboratories, Burlingame, CA, USA), and streptavidin-Alexa-488 fluorescent marker (Invitrogen).

\section{Immunofluorescence double-staining}

OCT-embedded scalp skin sections ( $7 \mu \mathrm{m})$ were fixed in ice-cold acetone/methanol $(8: 2, \mathrm{v} / \mathrm{v})$, and incubated with $0.3 \%$ hydrogen peroxide for $15 \mathrm{~min}$, protein block (Biogenex) for $20 \mathrm{~min}$, anti-CD200 for $30 \mathrm{~min}$, and anti-mouse lgG1 fluorescein isothiocyanate-conjugated antibodies (Caltag/Invitrogen) for $10 \mathrm{~min}$. Sections were then fixed in $2 \%$ paraformaldehyde containing $1 \%$ Triton X-100 for 10 min at $4{ }^{\circ} \mathrm{C}$, followed by anti-Ptch (30'), biotinylated anti-rabbit antibody (Vector Laboratories) (10'), and steptavidin-Alexa-594 (10') (Invitrogen). Images were captured on a Zeiss fluorescence microscope and overlay was performed using Spot Advanced software.

\section{Plasmid construction, lentiviral production and cell culture}

Human Gli1 cDNA (GenBank \#BC013000) in pOTB7 vector was purchased from OpenBiosystems (Huntsville, AL, USA), and used as template to produce blunt-end PCR products using Phusion ${ }^{\mathrm{TM}}$ 
DNA polymerase (New England Biolabs, Ipswich, MA, USA), and the following PCR primers: $5^{\prime}$-CAC-CAT-GTT-CAA-CTC-GATGAC-CCC-3' (forward) and 5'-TTA-GGC-ACT-AGA-GTT-GAGGAA-TTC-3' (reverse). The resulting Gli1 CDNA was cloned in a pENTR $^{\text {TM }}$ TOPO $^{\circledR}$ vector (Invitrogen). All constructions were verified by sequencing (University of Michigan DNA Sequencing Core). Subsequent subcloning into lentiviral vector (pLenti4/TO/V5-DEST; Invitrogen) and viral particles generation in 293-FT cells were performed as previously described (Stoll et al., 2009). NTert-2G KCs (primary KCs immortalized by stable expression of human telomerase catalytic domain TERT) (Dickson et al., 2000) were kindly provided by Dr James G. Rheinwald (Harvard Medical School, Boston, MA, USA). Human KC cell lines stably expressing Gli1 (NTert-Gli1) or eGFP (NTert-GFP, negative control) were generated and cultured as previously described (Stoll et al., 2009).

\section{Statistical analysis}

Data are expressed as mean \pm standard error of the mean. Comparisons among groups were made with the paired or unpaired Student's $t$-test. All $P$-values are two-tailed, and considered significant when less than 0.05 .

\section{Acknowledgments}

We thank Suzan Rehbine, LPN, for help with volunteer recruitment and scalp biopsies, Craig Hammerberg, PhD, for helpful suggestions, and Zachary Miller for his help with statistical analysis. We also thank James Rheinwald, PhD, for his generous gift of NTERT cells. This work was supported in part by an American Skin Association Research Scholar Award to LR.

\section{References}

Adolphe C, Narang M, Ellis T, Wicking C, Kaur P, Wainwright B (2004) An in vivo comparative study of sonic, desert and Indian hedgehog reveals that hedgehog pathway activity regulates epidermal stem cell homeostasis. Development 131, 5009-5019.

Athar M, Tang XW, Lee JL, Kopelovich L, Kim AL (2006) Hedgehog signalling in skin development and cancer. Exp. Dermatol. 15, 667677.

Barrandon Y, Green H (1987) Three clonal types of keratinocyte with different capacities for multiplication. Proc. Natl Acad. Sci. USA 84, 2302-2306.

Blanpain C, Lowry WE, Geoghegan A, Polak L, Fuchs E (2004) Selfrenewal, multipotency, and the existence of two cell populations within an epithelial stem cell niche. Cell 118, 635-648.

Boyer MJ, Cheng T (2008) The CDK inhibitors: potential targets for therapeutic stem cell manipulations? Gene Ther. 15, 117-125.

Chuang PT, McMahon AP (1999) Vertebrate hedgehog signalling modulated by induction of a hedgehog-binding protein. Nature 397, 617-621.

Claudinot S, Nicolas M, Oshima H, Rochat A, Barrandon Y (2005) Long-term renewal of hair follicles from clonogenic multipotent stem cells. Proc. Natl Acad. Sci. USA 102, 14677-14682.
Commo S, Bernard BA (1997) Immunohistochemical analysis of tissue remodelling during the anagen-catagen transition of the human hair follicle. Br. J. Dermatol. 137, 31-38.

Conboy IM, Conboy MJ, Smythe GM, Rando TA (2003) Notch-mediated restoration of regenerative potential to aged muscle. Science 302, 1575-1577.

Cotsarelis G, Sun TT, Lavker RM (1990) Label-retaining cells reside in the bulge area of pilosebaceous unit: implications for follicular stem cells, hair cycle, and skin carcinogenesis. Cell 61, 1329-1337.

Di Marcotullio L, Ferretti E, Greco A, De Smaele E, Po A, Sico MA, Alimandi M, Giannini G, Maroder M, Screpanti I, Gulino A (2006) Numb is a suppressor of hedgehog signalling and targets Gli1 for Itch-dependent ubiquitination. Nat. Cell Biol. 8, 1415-1423.

Dickson MA, Hahn WC, Ino Y, Ronfard V, Wu JY, Weinberg RA, Louis DN, Li FP, Rheinwald JG (2000) Human keratinocytes that express hTERT and also bypass a p16(INK4a)-enforced mechanism that limits life span become immortal yet retain normal growth and differentiation characteristics. Mol. Cell. Biol. 20, 1436-1447.

Dierks C, Beigi R, Guo G-R, Zirlik K, Stegert MR, Manley P, Trussell C, Schmitt-Graeff A, Landwerlin K, Veelken H, Warmuth M (2008) Expansion of Bcr-Abl-positive leukemic stem cells is dependent on hedgehog pathway activation. Cancer Cell 14, 238-249.

Edelberg JM, Ballard VL (2008) Stem cell review series: regulating highly potent stem cells in aging: environmental influences on plasticity. Aging Cell 7, 599-604.

Fiuraskova M, Brychtova S, Kolar Z, Kucerova R, Bienova M (2005) Expression of beta-catenin, p63 and CD34 in hair follicles during the course of androgenetic alopecia. Arch. Dermatol. Res. 297, 143-146.

Fuchs E (2008) Skin stem cells: rising to the surface. J. Cell Biol. 180, 273-284.

Ghali L, Wong ST, Green J, Tidman N, Quinn AG (1999) Gli1 protein is expressed in basal cell carcinomas, outer root sheath keratinocytes and a subpopulation of mesenchymal cells in normal human skin. J. Invest. Dermatol. 113, 595-599.

Giangreco A, Qin M, Pintar JE, Watt FM (2008) Epidermal stem cells are retained in vivo throughout skin aging. Aging Cell 7, 250-259.

Gritli-Linde A, Hallberg K, Harfe BD, Reyahi A, Kannius-Janson M, Nilsson J, Cobourne MT, Sharpe PT, McMahon AP, Linde A (2007) Abnormal hair development and apparent follicular transformation to mammary gland in the absence of hedgehog signaling. Dev. Cell 12, 99-112.

Grotendorst GR, Okochi H, Hayashi N (1996) A novel transforming growth factor beta response element controls the expression of the connective tissue growth factor gene. Cell Growth Differ. 7, 469480.

Ingham PW, McMahon AP (2001) Hedgehog signaling in animal development: paradigms and principles. Genes Dev. 15, 3059-3087.

Iseki S, Araga A, Ohuchi H, Nohno T, Yoshioka H, Hayashi F, Noji S (1996) Sonic hedgehog is expressed in epithelial cells during development of whisker, hair, and tooth. Biochem. Biophys. Res. Commun. 218, 688-693.

Ito M, Liu Y, Yang Z, Nguyen J, Liang F, Morris RJ, Cotsarelis G (2005) Stem cells in the hair follicle bulge contribute to wound repair but not to homeostasis of the epidermis. Nat. Med. 11, 1351-1354.

Jaks V, Barker N, Kasper M, van EsJH, Snippert HJ, Clevers H, Toftgard R (2008) Lgr5 marks cycling, yet long-lived, hair follicle stem cells. Nat. Genet. 40, 1291-1299.

Janzen $V$, Forkert R, Fleming HE, Saito $Y$, Waring MT, Dombkowski DM, Cheng T, DePinho RA, Sharpless NE, Scadden DT (2006) Stemcell ageing modified by the cyclin-dependent kinase inhibitor p16 ${ }^{\mathrm{INK} 4 a}$. Nature $\mathbf{4 4 3}, 421-426$. 
Kasper M, Schnidar H, Neill GW, Hanneder M, Klingler S, Blaas L, Schmid C, Hauser-Kronberger C, Regl G, Philpott MP, Aberger F (2006) Selective modulation of Hedgehog/GLI target gene expression by epidermal growth factor signaling in human keratinocytes. Mol. Cell. Biol. 26, 6283-6298.

Katoh Y, Katoh M (2006) Hedgehog signaling pathway and gastrointestinal stem cell signaling network (review). Int. J. Mol. Med. 18, 1019-1023.

Kloepper JE, Tiede S, Brinckmann J, Reinhardt DP, Meyer W, Faessler R, Paus R (2008) Immunophenotyping of the human bulge region: the quest to define useful in situ markers for human epithelial hair follicle stem cells and their niche. Exp. Dermatol. 17, 592-609.

Krause K, Foitzik K (2006) Biology of the hair follicle: the basics. Semin. Cutan. Med. Surg. 25, 2-10.

Krishnamurthy J, Ramsey MR, Ligon KL, Torrice C, Koh A, BonnerWeir S, Sharpless NE (2006) p16INK4a induces an age-dependent decline in islet regenerative potential. Nature 443, 453-457.

Levy V, Lindon C, Harfe BD, Morgan BA (2005) Distinct stem cell populations regenerate the follicle and interfollicular epidermis. Dev. Cell 9, 855-861.

Levy V, Lindon C, Zheng Y, Harfe BD, Morgan BA (2007) Epidermal stem cells arise from the hair follicle after wounding. FASEB J. 21, 1358-1366.

Li L, Mignone J, Yang M, Matic M, Penman S, Enikolopov G, Hoffman RM (2003) Nestin expression in hair follicle sheath progenitor cells. Proc. Natl Acad. Sci. USA 100, 9958-9961.

Limat A, French LE, Blal L, Saurat J-H, Hunziker T, Salomon D (2003) Organotypic cultures of autologous hair follicle keratinocytes for the treatment of recurrent leg ulcers. J. Am. Acad. Dermatol. 48, 207214.

Liu Y, Lyle S, Yang Z, Cotsarelis G (2003) Keratin 15 promoter targets putative epithelial stem cells in the hair follicle bulge. J. Invest. Dermatol. 121, 963-968.

Liu S, Dontu G, Mantle ID, Patel S, Ahn NS, Jackson KW, Suri P, Wicha MS (2006) Hedgehog signaling and Bmi-1 regulate self-renewal of normal and malignant human mammary stem cells. Cancer Res. 66, 6063-6071.

Machold R, Hayashi S, Rutlin M, Muzumdar MD, Nery S, Corbin JG, Gritli-Linde A, Dellovade T, Porter JA, Rubin LL, Dudek H, McMahon $A P$, Fishell G (2003) Sonic hedgehog is required for progenitor cell maintenance in telencephalic stem cell niches. Neuron 39, 937950.

Martinelli DC, Fan CM (2007) Gas1 extends the range of hedgehog action by facilitating its signaling. Genes Dev. 21, 1231-1243.

Michel M, Torok N, Godbout MJ, Lussier M, Gaudreau P, Royal A, Germain L (1996) Keratin 19 as a biochemical marker of skin stem cells in vivo and in vitro: keratin 19 expressing cells are differentially localized in function of anatomic sites, and their number varies with donor age and culture stage. J. Cell Sci. 109, 1017-1028.

Molofsky AV, Slutsky SG, Joseph NM, He S, Pardal R, Krishnamurthy J, Sharpless NE, Morrison SJ (2006) Increasing p16INK4a expression decreases forebrain progenitors and neurogenesis during ageing. Nature 443, 448-452.

Morris RJ, Liu Y, Marles L, Yang Z, Trempus C, Li S, Lin JS, Sawicki JA, Cotsarelis G (2004) Capturing and profiling adult hair follicle stem cells. Nat. Biotechnol. 22, 411-417.

Neill GW, Harrison WJ, Ikram MS, Williams TD, Bianchi LS, Nadendla SK, Green JL, Ghali L, Frischauf AM, O'Toole EA, Aberger F, Philpott MP (2008) GLI1 repression of ERK activity correlates with colony formation and impaired migration in human epidermal keratinocytes. Carcinogenesis 29, 738-746.
Nielsen CM, Williams J, van denBrink GR, Lauwers GY, Roberts DJ (2004) Hh pathway expression in human gut tissues and in inflammatory gut diseases. Lab. Invest. 84, 1631-1642.

Niemann C, Unden AB, Lyle $S$, Zouboulis CC, Toftgard R, Watt FM (2003) Indian hedgehog and beta-catenin signaling: role in the sebaceous lineage of normal and neoplastic mammalian epidermis. Proc. Natl Acad. Sci. USA 100, 11873-11880.

Ninkovic J, Stigloher C, Lillesaar C, Bally-Cuif L (2008) Gsk3beta/PKA and Gli1 regulate the maintenance of neural progenitors at the midbrain-hindbrain boundary in concert with $E(S p l)$ factor activity. Development 135, 3137-3148.

Ohyama M, Terunuma A, Tock CL, Radonovich MF, Pise-Masison CA, Hopping SB, Brady JN, Udey MC, Vogel JC (2006) Characterization and isolation of stem cell-enriched human hair follicle bulge cells. J. Clin. Invest. 116, 249-260.

Olsen CL, Hsu PP, Glienke J, Rubanyi GM, Brooks AR (2004) Hedgehog-interacting protein is highly expressed in endothelial cells but down-regulated during angiogenesis and in several human tumors. BMC Cancer 4, 43.

Orringer JS, Hammerberg C, Lowe L, Kang S, Johnson TM, Hamilton T, Voorhees JJ, Fisher GJ (2006) The effects of laser-mediated hair removal on immunohistochemical staining properties of hair follicles. J. Am. Acad. Dermatol. 55, 402-407.

Palma V, Lim DA, Dahmane N, Sanchez P, Brionne TC, Herzberg CD, Gitton Y, Carleton A, Alvarez-Buylla A, Ruiz i Altaba A (2005) Sonic hedgehog controls stem cell behavior in the postnatal and adult brain. Development 132, 335-344.

Poblet E, Jimenez-Acosta F, Rocamora A (1994) QBEND/10 (antiCD34 antibody) in external root sheath cells and follicular tumors. J. Cutan. Pathol. 21, 224-228.

Poblet E, Jimenez F, Godinez JM, Pascual-Martin A, Izeta A (2006) The immunohistochemical expression of CD34 in human hair follicles: a comparative study with the bulge marker CK15. Clin. Exp. Dermatol. 31, 807-812.

Ressler S, Bartkova J, Niederegger H, Bartek J, Scharffetter-Kochanek $\mathrm{K}$, Jansen-Durr P, Wlaschek M (2006) p16INK4A is a robust in vivo biomarker of cellular aging in human skin. Aging Cell 5, 379-389.

Rittié L, Kang S, Voorhees JJ, Fisher GJ (2008) Induction of collagen by estradiol: difference between sun-protected and photodamaged human skin in vivo. Arch. Dermatol. 144, 1129-1140.

Rittié L, Fisher GJ, Voorhees JJ (2010) Aging and photoaging of the skin. In Therapy of Skin Diseases. (Krieg T, Bickers DR, Miyachi Y, eds). Berlin/Heidelberg/New York: Springer-Verlag. In Press.

Rosenblum MD, Yancey KB, Olasz EB, Truitt RL (2006) CD200, a "no danger" signal for hair follicles. J. Dermatol. Sci. 41, 165-174.

Ross J, Li L (2006) Recent advances in understanding extrinsic control of hematopoietic stem cell fate. Curr. Opin. Hematol. 13, 237242.

Rubin LL, de Sauvage FJ (2006) Targeting the hedgehog pathway in cancer. Nat. Rev. Drug Discov. 5, 1026-1033.

Secker GA, Shortt AJ, Sampson E, Schwarz QP, Schultz GS, Daniels JT (2008) TGFbeta stimulated re-epithelialisation is regulated by CTGF and Ras/MEK/ERK signalling. Exp. Cell Res. 314, 131-142.

Seppala M, Depew MJ, Martinelli DC, Fan CM, Sharpe PT, Cobourne MT (2007) Gas1 is a modifier for holoprosencephaly and genetically interacts with sonic hedgehog. J. Clin. Invest. 117, 1575-1584.

Shapiro Gl (2006) Cyclin-dependent kinase pathways as targets for cancer treatment. J. Clin. Oncol. 24, 1770-1783.

Sherr CJ, Roberts JM (1999) CDK inhibitors: positive and negative regulators of G1-phase progression. Genes Dev. 13, 1501-1512.

Sicklick JK, Li YX, Melhem A, Schmelzer E, Zdanowicz M, Huang JW, Caballero M, Fair JH, Ludlow JW, McClelland RE, Reid LM, Diehl 
AM (2006) Hedgehog signaling maintains resident hepatic progenitors throughout life. Am. J. Physiol. 290, G859-G870.

Stoll SW, Johnson JL, Bhasin A, Johnston A, Gudjonsson JE, Rittié L, Elder JT (2009) Metalloproteinase-mediated, context-dependent function of amphiregulin and HB-EGF in human keratinocytes and skin. J. Invest. Dermatol. In Press.

Sudo K, Ema H, Morita Y, Nakauchi H (2000) Age-associated characteristics of murine hematopoietic stem cells. J. Exp. Med. 192, 1273-1280.

Trowbridge JJ, Scott MP, Bhatia M (2006) Hedgehog modulates cell cycle regulators in stem cells to control hematopoietic regeneration. Proc. Natl Acad. Sci. USA 103, 14134-14139.

Tumbar T, Guasch G, Greco V, Blanpain C, Lowry WE, Rendl M, Fuchs E (2004) Defining the epithelial stem cell niche in skin. Science 303, 359-363.

Vidal VPI, Chaboissier MC, Lutzkendorf S, Cotsarelis S, Mill P, Hui CC, Ortonne N, Ortonne JP, Schedl A (2005) Sox9 is essential for outer root sheath differentiation and the formation of the hair stem cell compartment. Curr. Biol. 15, 1340-1351.

Vincent S, Perrimon N, Axelrod JD (2008) Hedgehog and wingless stabilize but do not induce cell fate during Drosophila dorsal embryonic epidermal patterning. Development 135, 2767-2775.

Zhao C, Chen A, Jamieson CH, Fereshteh M, Abrahamsson A, Blum J, Kwon HY, Kim J, Chute JP, Rizzieri D, Munchhof M, VanArsdale T, Beachy PA, Reya T (2009) Hedgehog signalling is essential for maintenance of cancer stem cells in myeloid leukaemia. Nature $\mathbf{4 5 8}$ 776-779.
Zhou JX, Jia LW, Liu WM, Miao CL, Liu S, Cao YJ, Duan EK (2006) Role of sonic hedgehog in maintaining a pool of proliferating stem cells in the human fetal epidermis. Hum. Reprod. 21, 1698-1704.

Zouboulis CC, Adjaye J, Akamatsu H, Moe-Behrens G, Niemann C (2008) Human skin stem cells and the ageing process. Exp. Gerontol. 43, 986-997.

\section{Supporting Information}

Additional supporting information may be found in the online version of this article:

Fig. S1 Morphology of plucked human scalp hair follicles.

Fig. S2 Cyclin-dependant kinase inhibitors are not specifically expressed in bulge cells, nor altered with aging in human skin in vivo.

As a service to our authors and readers, this journal provides supporting information supplied by the authors. Such materials are peer-reviewed and may be re-organized for online delivery, but are not copy-edited or typeset. Technical support issues arising from supporting information (other than missing files) should be addressed to the authors. 